\section{O narrar e o Outro: uma reflexão sobre a alteridade na construção de narrativas jornalísticas}

Dayane do Carmo Barretos
Recebido em: 12.09.20

Aprovado em: 21.02.21

Dayane do

Carmo Barretos

Doutoranda em Comunicação da Universidade Federal de Minas Gerais

E-mail: dayanecbarretos@gmail.com

\title{
Resumo:
}

A relação entre os sujeitos no processo de constituição de narrativas jornalísticas é nossa grande inquietação neste trabalho. A fim de cercá-la, propomos uma problematização a partir de reflexões que compreendem o narrar enquanto ação e as narrativas como relevadoras de processos, tempos e experiências vivenciados entre sujeitos e também no seio social. O Outro nos aparece sempre à espreita, em uma lógica própria da relação entre o Eu e o Outro, da qual as subjetividades são importante parte constituinte. É com o Outro que ocorrem os encontros e as tensões, a partilha e o confronto que estão invariavelmente presentes na prática jornalística, na apuração, na escrita e também no próprio exercício do papel mediador que a narrativa exerce. Assim, pela via da alteridade acreditamos ser possível promover uma importante reflexão acerca do ato de narrar no âmbito da atividade jornalística como um todo, possibilitando um olhar ampliado para as questões que dizem respeito aos sujeitos.

Palavras-chave: Narrativas jornalísticas. Alteridade. Sujeitos.

The narrate and the Other: a reflection about the alterity in the construction of journalistic narratives

\begin{abstract}
:
The relationship between the subjects in the process of constituting journalistic narratives is our great concern in this work. To discuss this issue, we propose a problematization based on reflections that comprise narrating as an action and narratives as relevant to processes, times and experiences lived between subjects and also in the social context. The other always appears on the prowl, in a logic proper to the relationship between the self and the other, of which subjectivities are an important constituent part. It is with the other that the encounters and tensions, the sharing and the confrontation that are invariably present in the journalistic practice, in the investigation, in the writing and also in the very exercise of the mediating role that the narrative plays, occur. Thus, by way of otherness, we believe it is possible to promote an important reflection on the act of narrating within the scope of journalistic activity, enabling an expanded look at the issues that concern the subjects.
\end{abstract}

Keywords: Journalistic narratives. Alterity. Subjects.
Estudos em Jornalismo e Mídia v.18, n.1, jan./jun. 2021.

ISSNe 1984-6924 
narrar como condição da nossa existência enquanto sujeitos que, por viver em sociedade, partilhamos histórias, tanto de nós mesmos, como dos outros, é nosso tema central aqui. Para tanto, propomos um olhar para o ato de narrar no âmbito da prática jornalística a partir de uma chave fundamental para a compreensão da dimensão relacional dessa atividade: a alteridade. Com isso, a relação com o Outro, própria do jornalismo, bem como dos seus vestígios no cotidiano dos repórteres, é central para os tensionamentos que realizamos nessa discussão.

Este artigo é parte de um movimento mais amplo de pesquisa em que buscamos compreender o encontro de sujeitos e o compartilhamento de sentidos possível pelas narrativas de jornalistas brasileiras, mais precisamente pelos processos de escrita, ou seja, de constituição desse narrar, dessas narradoras e desses diversos Outros. Investigar as relações entre os sujeitos é admitir de saída uma narrativa jornalística múltipla, ao mesmo tempo que limitada a determinado olhar, a determinada voz, fadada a não dar conta de uma totalidade. Aí está o desafio e a riqueza do narrar o Outro: alcançar a dimensão do encontro mesmo admitindo a impossibilidade de alcançar pela escrita a totalidade do sujeito.

Em um primeiro momento iremos nos debruçar sobre a narrativa e o ato de narrar que se localiza temporalmente e organiza a nossa experiência. Depois, adentraremos nas discussões acerca da alteridade, do Outro. Partimos do pressuposto de que as reflexões sobre a alteridade, há muito tempo fonte de inquietação da filosofia e dos estudos da linguagem, ganham novos contornos ao levarmos em conta as novas relações entre sujeitos que a mídia promove e instaura. É necessário, portanto, alargarmos o horizonte das discussões sobre alteridade para, posteriormente, pensá-la sob uma perspectiva jornalística.

\section{O narrar}

Narrar é um modo de constituir vínculos (MARTINO, 2016). A partilha de sentidos propiciada pela narrativa revela-se tanto na prática jornalística como na relação entre os sujeitos na sociedade. Voltar o olhar para a construção da narrativa jornalística, refletindo sobre o sujeito que narra, a sua afinidade com os personagens e com as vozes que trata e o leitor, que, de alguma forma, já está presente no ato de narrar, permite pensá-la enquanto parte de um processo dinâmico que envolve não só a construção textual, mas também o processo comunicativo como um todo, levando em conta os sujeitos envolvidos e o contexto histórico-cultural.

Para Leal (2013, p. 28), "narrar é estabelecer um modo de compreensão do mundo, de configurar experiências e realidades, de comunicar-se com o outro". Assim, é impossível desvincular o ato de narrar da experiência dos sujeitos e, em contrapartida, essa experiência encontra-se em consonância direta com a temporalidade de que trata. No caso do jornalismo, o presente, e ampliando o espectro de abordagem, o próprio contemporâneo.

A afirmação de Leal (2013) também chama atenção para outro ponto: a importância da narrativa na construção da nossa experiência de mundo. Ao narrar é possível dar significado às nossas vivências. Ao eleger a narrativa como objeto possibilita-se aquilo que Leal (2006) chama de olhar narrativizante, "fazendo emergir as formas de articulação do cotidiano" (LEAL, 2006, p. 22). Dessa forma, para além de uma análise que abarque a estrutura do relato, os personagens e as vozes, o estudo da narrativa revela algo sobre as relações entre esferas culturais, políticas, ideológicas e, por que não, afetivas, que se instauram no cotidiano. "Um olhar narrativizante constitui-se como um modo de se perguntar sobre experiências, saberes, mundos e forças presentes na mídia, na rua, na vida.” (LEAL, 2006, p. 27). 
É ao olhar para as narrativas buscando compreender o modo como elas se constituem, examinando os saberes a ela vinculados, como também o que os temas e personagens abordados dizem sobre as visibilidades em jogo no contemporâneo, que nos aproximamos da globalidade da prática jornalística em seu caráter relacional.

Desse modo, estudar a narrativa no âmbito do jornalismo é refletir sobre o todo que cerca essa produção, não olhar apenas separadamente para o conteúdo, ou para o suporte, ou para os atores envolvidos. Leal (2013) destaca as características do fazer jornalístico as quais devem ser perscrutadas ao se pensar sobre suas produções: "sendo o jornalismo um fenômeno cultural, suas regras e procedimentos são marcados por valores, características e percepções que o vinculam a tempos e espaços particulares" (LEAL, 2013, p. 26). É no cruzamento entre as instâncias do processo comunicativo e as tensões do mundo social que habita o saber promovido pela narrativa jornalística. Para analisar a narrativa jornalística, é necessário entendê-la como parte desse processo e não a recortar do seu entorno. Em se tratando de jornalismo, o tempo e o espaço a que o conteúdo está atrelado são essenciais para sua compreensão.

Assim, temos que a escolha do modo de narrar não é gratuita, tampouco diz respeito apenas às escolhas do repórter ou às determinações da empresa jornalística, "tais procedimentos de escrita, antes de serem permanentes, neutros e a-históricos, estão articulados às tensões que regulam e perpassam o fazer jornalístico e que o inserem no tempo e na cultura" (LEAL, 2013, p. 26). É essa ideia ampliada de narrativa jornalística, ancorada em uma discussão sobre o jornalismo, que serve como base para essa discussão.

Resende (2011) indica uma dimensão paradoxal da narrativa jornalística: basear-se no real e constituir-se através da linguagem. "Olhar para a narrativa significa enfrentar o dilema de saber que o discurso que obedece a lei de se referendar no real é também estruturado - e tecido - a partir do simbólico" (RESENDE, 2011, p. 125). Desse modo, é importante ressaltar que a linguagem não contempla a realidade em sua totalidade exatamente por se constituir de material simbólico. Seguindo essa linha, pode-se concluir que a própria proposta dos estudos da narrativa parte da ideia de um compartilhamento de sentidos ao invés da ideia de transmissão de informação (RESENDE, 2011), muitas vezes atrelada à prática jornalística. É por meio das escolhas feitas pelo repórter, tanto durante a apuração quanto no momento da escrita, que o relato vai sendo construído e, assim, uma visão de mundo é partilhada com os leitores que dela se apropriam, transformando-a.

O jornalista como protagonista do ato, quando se reposiciona no lugar do humano, cria possibilidades de encontro. Articulando-se no tecido da vida, ele deixa, através do texto, de ocupar o lugar de dono da lei, para tornar-se um observador, tanto quanto o é aquele para quem escreve. (RESENDE, 2009, p. 38)

Ao se livrar do imperativo do retrato absoluto do real, uma vez que narrativas são tanto "devedoras de uma referencialidade como portadoras de simbólico" (RESENDE, 2011, p. 132), a narrativa jornalística liberta-se de uma perspectiva que a tratava enquanto sinônimo de "forma" para ganhar potencialidades, tornando-se "ação". Ela é reveladora tanto dos mistérios por trás dos fatos como da necessidade de se construir diálogos; produz sentidos mais que efeitos (RESENDE, 2011). Já o jornalismo, por intermédio da narrativa, tem o papel de "entrelaçar mundos e tecer redes com todos os percalços e potências de que este gesto se constitui" (RESENDE, 2011, p. 134).

Schwaab (2014) elucida alguns pontos sobre esse narrar que é ação e que dialoga com a ideia de compartilhamento tão cara a este trabalho. Para o autor, "o narrar como ação, de igual modo, nos convida a pensar de forma radical a inter-relação entre os sujeitos e a essência da comunicação" (SCHWAAB, 2014, p. 32). 
A partir de conceitos abordados pelo filósofo Paul Ricoeur (1913-2005), que, aliás, também serve como base teórica para Resende (2011) e Leal (2013), Schwaab (2014) destaca que é por meio da narrativa que o sujeito se apropria do tempo, tornando-o palpável, inteligível. "O tempo e a ação se tornam humanos na medida em que são narrativamente organizados" (SCHWAAB, 2014, p. 32).

Para Schwaab (2014), a narrativa possui a capacidade de reconfigurar o que já estava configurado no mundo de alguma forma. Nesse sentido, cultiva uma relação direta com a ação.

A narrativa oferece a possibilidade de o discurso ser entendido sobre a ação, permitindo falar de coisas que acontecem não apenas no tempo, mas também ao longo do tempo, incluindo causas e consequências, mesmo que distantes cronologicamente, algo que é feito contando uma história sobre a ação humana e seu significado (SCHWAAB, 2014, p. 35).

Embora Ricoeur (1994) direcione sua reflexão sobre narrativa para o campo da História e para a Literatura, Schwaab (2014) acredita que o jornalismo aflore na interface entre ambas, o que faz com que a sua discussão seja pertinente para essa área. A perspectiva de Ricoeur (1994) traz à tona questões importantes para os estudos atuais sobre narrativa jornalística, uma vez que o autor coloca em cena o tempo, o contexto histórico e os sujeitos envolvidos naquilo que ele chama de tessitura da intriga. A narrativa, por meio da intriga, é uma articulação de "processos culturais que articulam a experiência inteira" (RICOEUR, 1994, p. 92). Desse modo, vale a pena atermo-nos um pouco mais às proposições do filósofo.

Sua discussão sobre a narrativa avança a partir de uma articulação particularmente pertinente para o que buscamos expor neste artigo e que nos permite compreender a integralidade do processo narrativo: a tríplice mimese.

O conceito de mimese como imitação na obra de Ricoeur não se baseia em um decalque do real, mas diz respeito à ideia de uma imitação criadora (RICOEUR, 1994). Como já dito, a perspectiva do autor promove um movimento que vai da ação ao texto e dele retorna à ação. Esse percurso é propiciado por meio das três mimeses, conforme destaca: "é construindo a relação entre os três modos miméticos que constituo a mediação entre tempo e narrativa. É essa própria mediação que passa pelos três passos da mimese" (RICOEUR, 1994, p. 87).

A mimese I diz respeito ao mundo prefigurado, já que, "se, com efeito, a ação pode ser narrada, é porque ela já está articulada em signos, regras, normas: é, desde sempre, simbolicamente mediatizada" (RICOEUR, 1994, p. 91, grifo do autor). Assim, visto que a imitação é possível, há de haver um mundo a ser imitado, com suas estruturas. Além disso, há de haver algo que permita a articulação desses traços estruturais, um modo de compreendê-los; esse algo que acionamos quando desejamos compreender alguma coisa é a mediação simbólica. Essa articulação simbólica, por sua vez, possui caráter temporal, de onde vem a capacidade de narrar e a própria necessidade de fazê-lo. São essas três dimensões, estrutural, simbólica e temporal, que definem essa mimese. Nas palavras de Ricoeur (1994, p. 88), "a composição da intriga está enraizada numa pré-compreensão do mundo e da ação: de suas estruturas inteligíveis, de suas fontes simbólicas e de seu caráter temporal”.

Seguindo essa linha, se é pressuposto que há a necessidade de que o mundo de que trata a narrativa seja compreensível para o leitor, ou seja, que o sujeito que narra e o que lê compartilhem de saberes que permitam a partilha do sentido narrado; é esse momento mimético que serve de base para essa construção de significado.

Vê-se qual é, na sua riqueza, o sentido de mimese I: imitar ou representar ação é, primeiro, pré-compreender o que ocorre com o agir humano: com sua semântica, com sua simbólica, 
com sua temporalidade. É sobre essa pré-compreensão, comum ao poeta e a seu leitor, que se ergue a tessitura da intriga e, com ela, a mimética textual e literária. (RICOEUR, 1994, p. 101)

É exatamente a mimese II que tem a função de interrupção, é ela que abre o mundo da composição poética (RICOEUR, 1994). Ou seja, trata-se da dimensão textual da narrativa, a qual já foi por vezes compreendida como a própria narrativa em si, mas para o filósofo é uma das suas fases, um componente mediador que levaria à terceira mimese. Ela faz a mediação entre a prefiguração, da mimese I, e a refiguração, da mimese III. O autor define o papel mediador da tessitura da intriga como "um estágio da experiência prática que a precede e outro que a sucede" (RICOEUR, 1994, p. 87). É por meio dela que o leitor faz o caminho da mimese I até a III.

Assim, é nessa fase que se torna possível estabelecer uma relação entre os acontecimentos que servem como matéria prima para a narrativa e um contexto ampliado da experiência humana. Além disso, a mimese II articula as duas dimensões temporais, a episódica e a configurante, sendo que, enquanto a primeira instiga uma linearidade, a segunda faz com que uma sucessão de acontecimentos se torne uma totalidade significante. A mimese II é a configuração da intriga em si, é ela que "marca a intersecção entre o mundo do texto e o mundo do ouvinte ou leitor" (RICOEUR, 1994, p. 110).

Por fim, a mimese III marca o retorno ao mundo da experiência, ao tempo do agir. Segundo Ricoeur (1994, p. 110), "a narrativa tem seu sentido pleno quando é restituída ao tempo do agir e do padecer". É nessa fase que se insere o ato da leitura como "operador que conjuga mimese II e mimese III. É o último vetor da refiguração do mundo da ação sob o signo da intriga" (RICOEUR, 1994, p. 118).

Desse modo, é na mimese III que o leitor exerceria seu papel de reconfiguração, não de forma a fechar um ciclo, mas possibilitando a proliferação das histórias, permitindo assim que esse ciclo se reinicie. "O círculo hermenêutico entre a narrativa e o tempo não cessa assim de renascer do círculo que os estágios de mimese formam." (RICOEUR, 1994, p. 117). Essa inserção do leitor enquanto o sujeito que reconfiguraria a narrativa, dando novo sentido e reiniciando o processo, é importante para a reflexão que buscamos instigar aqui, pois dialoga com a ideia de compartilhamento de sentidos, além de propiciar um olhar alargado que leve em consideração o processo comunicativo como um todo.

A articulação entre as três mimeses comprova a hipótese do autor de que há uma relação, que não é acidental, entre o caráter temporal da experiência humana e a atividade de narrar. "O tempo torna-se humano na medida em que é articulado de um modo narrativo, e que a narrativa atinge o seu pleno significado quando se torna uma condição da existência temporal" (RICOEUR, 1994, p. 85). Com isso, a narrativa produz sentido sobre o tempo que, por sua vez, afeta a construção narrativa, por meio da experiência temporal.

Uma abordagem que pressupõe o leitor como aquele que recoloca a narrativa em movimento e contribui para destacar a dinâmica circular do processo de atribuição de sentidos e construção de significação sobre a realidade retratada. Sobre esse viés, Leal (2013, p. 33) considera que "o receptor não é o fim da narrativa, mas a condição para sua perpetuação". Uma perspectiva que se aproxima da ideia da terceira mimese proposta por Ricoeur (1994) e de outras discussões do filósofo acerca do papel determinante do leitor, como em $O$ si-mesmo como um outro em que ele afirma que "a narrativa faz parte da vida antes de se exilar da vida na escrita; ela volta à vida segundo as múltiplas vias da apropriação" (RICOEUR, 1991, p. 193). Tal apropriação só se efetiva pelo leitor.

Nesse esteio, uma nova conceituação do papel da narrativa faz-se pertinente. "As narrativas não apenas organizam, configuram a experiência humana como também indicam que essa disposição se dirige a um sentido, um fim, um destino e, porque não dizer, um destinatário" (LEAL, 2013, p. 32). 


\section{O Outro que constitui a narrativa}

Após delimitar a nossa compreensão da narrativa, caminhamos para um olhar a partir do Outro. Muito atrelada aos sujeitos e à narrativa a partir de uma perspectiva relacional, a discussão sobre a alteridade é central neste trabalho. Os estudos em jornalismo são capazes de articular a construção das narrativas jornalísticas com a representação do Outro e das diferenças. Conforme afirma Resende (2014, p. 209), "acreditamos, pois, que é no processo de construção narrativa - nos modos de encenação das notícias - que podemos revelar e avaliar alguns dos mecanismos de produção das diferenças". (RESENDE, 2014, p. 209). Assim, as próprias produções jornalísticas são reveladoras de mecanismos de identificação e inserção de diferenças que estão presentes no nosso cotidiano e são apropriadas pelo processo de organização de sentidos das narrativas a partir da dinâmica mimética proposta por Ricoeur (1994).

O entendimento do narrar como ação, e como forma de tornar a experiência inteligível, se complexifica a partir da relação com o Outro. Isso porque a configuração da experiência só é possível por ser partilhada, os sentidos se constituem no conflito entre as percepções do Eu e do Outro que, longe de estabelecerem uma relação harmoniosa, negociam, dialogam, fazem concessões, produzem conjuntamente aquilo que se tornará comum pela narrativa. O retorno ao tempo do agir e do padecer, para usar termos ricoeurianos, pressupõe o Outro, afinal, agimos sobre/com algo e/ou alguém e padecemos com algo e/ou alguém. Essa relação não depende apenas do Eu, mas do Eu e do Outro, do comum compartilhado. Desse modo, a alteridade integra necessariamente a experiência e, consequentemente, a narrativa.

Todorov (1983), em sua obra que trata do choque entre as culturas na conquista da América, distingue três eixos para problematizar a questão da alteridade pensando as diferenças que existem no real; são eles: axiológico, praxiológico e epistêmico. O plano axiológico diz sobre o julgamento de valor em que "o outro é bom ou mau, gosto dele ou não gosto dele” (TODOROV, 1983, p. 183). Já o plano praxiológico trata da relação de aproximação ou de distanciamento em relação ao Outro, em que "adoto valores do outro, identifico-me a ele; ou então assimilo o outro, impondo-lhe minha própria imagem; entre a submissão do outro há ainda um terceiro termo, que é a neutralidade, ou indiferença" (TODOROV, 1983, p. 183). Por último, o plano epistêmico define-se pela ação de conhecer ou ignorar a identidade do Outro. Sobre este terceiro plano, o autor ressalta que "aqui não há, evidentemente, nenhum absoluto, mas uma gradação infinita entre os estados de conhecimento inferiores e superiores" (TODOROV, 1983, p. 183).

Esses movimentos de julgamento, aproximação, distanciamento e conhecimento do Outro também podem ser observados ao nível do discurso, mais especificamente da construção discursiva do Outro na narrativa. $O$ risco aqui é reduzir o sujeito à categoria de objeto (TODOROV, 1983), conformando-o à minha própria expectativa sobre ele, ou designando-o a um papel pré-determinado por mim enquanto narrador. Conforme destaca Resende (2014, p. 212), “o outro, quando fala, fala sempre de um deslugar, porque invariavelmente fala através daqueles que lhes concedem este direito, uma condição antes de autoridade, muito distante do que se espera de um exercício de alteridade" (RESENDE, 2014, p. 212).

A alteridade e a construção discursiva do Outro só existem em relação, não se estabelecem a priori. Sobre esse aspecto, Todorov (1983) ressalta a importância do diálogo, exemplo de articulação que parte inevitavelmente de certa disponibilidade de um sujeito para com o Outro. "Ora, é falando ao outro (não dando-lhe ordens, mas dialogando com ele), e somente então, que reconheço nele uma qualidade de sujeito, comparável ao que eu mesmo sou" (TODOROV, 1983, p. 128, grifo do autor). É, portanto, por meio do diálogo que o indivíduo perde o caráter de objeto para tornar-se sujeito em sua totalidade. $\mathrm{O}$ autor ainda salienta o risco de se explorar o Outro não 
respeitando sua plenitude enquanto sujeito, como ocorreu durante a conquista da América e como pode ocorrer no discurso midiático atualmente. "Se a compreensão não for acompanhada de um reconhecimento pleno do outro como sujeito, então essa compreensão corre o risco de ser utilizada com vistas à exploração, ao "tomar"; o saber será subordinado ao poder" (TODOROV, 1983, p. 128).

Uma lógica parecida com essa possibilidade de se subordinar o saber, conhecimento que habitaria o plano epistêmico, ao poder, é abordada por Resende (2014) ao tratar da produção das diferenças proporcionada pela mídia, que estaria atrelada a um projeto de poder em voga no que o autor chama de capitalismo tardio.

Nesse contexto, parece importante notar que o processo de produção das diferenças, que
não resulta em relação de alteridade, é simplesmente parte de uma lógica do capitalismo
tardio - quando as máquinas de produção de informação e conhecimento ganham prima-
zia. E é, portanto, nesse quadro que, além de ser importante saber o que o discurso diz, é
fundamental investigar o que ele faz. (RESENDE, 2014, p. 217)

Mais do que uma simples análise dos efeitos do discurso, Resende (2014) propõe um alargamento das reflexões sobre a construção do Outro e das diferenças no discurso jornalístico. Ao destacar a importância do tema, o autor denuncia uma abordagem midiática que teria um papel fundamental na perpetuação da segregação e exclusão desse Outro, quando a fala deste não cabe no local predefinido pela mídia (e todos os jogos políticos e ideológicos que a envolvem). Seja esse Outro membro da periferia, um estrangeiro ou simplesmente alguém com quem não é possível chegar a um acordo, ou seja, estranhos, seja qual for a sua dimensão.

Continuando no esteio das reflexões sobre alteridade, as proposições do filósofo Emmanuel Levinas $(1982 ; 2005 ; 2008)$ nos auxiliam na compreensão da relação entre o Eu e o Outro por meio de uma abertura à Ética, para ele a filosofia primeira. Crítico à Ontologia, o autor entende a Ética como o que decorre da relação transcendente do $\mathrm{Eu}$ ao $\mathrm{Tu}$, em que o Outro é a prioridade absoluta a quem o Eu é impelido a responder. Essa alteridade radical insere em nosso horizonte de discussão uma centralidade do Outro, em que o si só existe por causa do Outro, em que o humano começa no devotar-se-ao-outro (LEVINAS, 2005).

Desse modo, o Outro demanda uma responsabilidade, aciona a solidariedade. Segundo Levinas (2005, p. 19), "o ser-em-si do ser persistente-em-ser supera-se na gratuidade do sair-de-si-para-o-outro, no sacrifício ou na possibilidade do sacrifício, na perspectiva da santidade". Essa relação, que em alguma medida demanda o sacrifício, é assimétrica, não prevê uma reciprocidade, o que a diferencia de uma proposta dialógica e a aproxima da Ética nos termos levinasianos. Assim, a intersubjetividade é pensada a partir dessa não-simetria em que "sou responsável por outrem sem esperar a recíproca, ainda que isso viesse a me custar a vida. A recíproca é assunto dele" (LEVINAS, 1982, p. 74).

É importante adentrarmos nessas bases do pensamento levinasiano para compreendermos a importância da linguagem na discussão que o autor propõe. A linguagem, para Levinas, é o lugar que origina a relação. Judith Butler (2011) destaca que "para Levinas, a situação do discurso consiste no fato de que a linguagem chega como um endereçamento que não desejamos e pelo qual somos, num sentido original, capturados, para não dizer - segundo os termos do próprio Levinas - feito cativos." (BUTLER, 2011, p. 23). Nesse ponto, ele não está tratando do discurso impessoal ideal, que objetificaria o Outro, mas de um discurso do qual não podemos desviar, em que o Outro aciona o Eu pela linguagem e demanda dele uma responsabilidade, da qual não se pode escapar.

Isso posto, ainda que pareça que o autor chegue a vislumbrar algo do processo comunicativo, ele nos coloca em um impasse, o diálogo proposto tem o Outro enquanto centro, transcendendo as percepções cognitivas do Eu. Dessa maneira, não há uma tomada de consciência do Outro, de compreensão desse Outro e um 
diálogo que se segue, ambos ocorrem de forma a confundir-se "dito de outra forma, da compreensão de outrem é inseparável sua vocação" (LEVINAS, 2005, p. 27). Butler (2011), ao refletir sobre a discussão de Levinas acerca do Outro enquanto condição da linguagem, considera que apenas na situação do discurso a que somos remetidos é que podemos fazer uso da linguagem, "é nesse sentido que o Outro é a condição do discurso. Se o Outro for anulado, também o será a linguagem" (BUTLER, 2011, p. 22). A linguagem é, por conseguinte, dependente da condição do discurso que o Outro instaura, não podendo sobreviver fora dela. É a partir dessa lógica que compreender o Outro e dirigir-lhe a palavra são processos simultâneos e interdependentes.

Nesse sentido, é necessário ter cautela ao tentar articular uma reflexão que aborde a linguagem levinasiana como algo que aponta para a linguagem escrita, ainda que esta escrita prime pela articulação com o Outro, uma vez que a escrita já é uma forma de racionalização dos sentidos que chegam por meio de uma tentativa de compreensão do Outro.

Uma tentativa de escapatória para esse impasse é tomarmos a linguagem enquanto potência promotora de diálogo, de compreensão do Outro no momento da relação, do encontro, uma vez que "a palavra delineia uma relação original" (LEVINAS, 2005, p. 27). Há, portanto, dois momentos que devem ser examinados ao tratarmos das interações entre sujeitos na prática jornalística: 1) a relação intersubjetiva repórter-personagem; 2) a constituição de sentidos sobre o Outro na narrativa jornalística. Sendo que a perspectiva de linguagem em Levinas (2005) nos auxilia a compreender esse primeiro processo, anterior ao segundo.

Levinas (2005) tratará da linguagem também em sua perspectiva ética, como aquilo que possibilita a articulação de proximidade com o Outro, de um Outro que permanece sempre Outro. Nessa relação, Eu e Tu são absolutamente distintos um do outro, individuais, a palavra que os une é conectora de liberdades. Nos termos do autor, "a palavra é, portanto, relação entre liberdades que não se limitam nem se negam, mas se afirmam reciprocamente" (2005, p. 61).

Essa relação entre liberdades coloca em cena uma possibilidade não-reducionista da linguagem, evitando a limitação do sujeito a uma ideia.

O eu é inefável, visto que falante por excelência; respondente, responsável. Outrem, como puro interlocutor, não é um conteúdo conhecido, qualificado, captável a partir de uma idéia geral qualquer, submetido a esta idéia. Ele faz face, não se referindo senão a si. É na palavra entre seres singulares que só vem se constituir a significação interindividual dos seres e das coisas, ou seja, a universalidade (LEVINAS, 2005, p. 50)

A resposta do Eu ao Outro advém de um despertar para o Outro incompatível com o individualismo e o egoísmo. Para o filósofo, o Outro entra sem pedir licença, ele desconcerta, exige uma responsabilidade. Responder ao Outro é um despertar ético. Seguindo essa linha, o conceito de rosto em Levinas emerge como $o$ que acionaria essa responsabilidade, que evoca o sacrifício.

Chamo rosto o que, assim, em outrem, diz respeito ao eu - me concerne - lembrando, por detrás da postura que ele exibe em seu retrato, seu abandono, seu desamparo e sua mortalidade, e seu apelo à minha antiga responsabilidade, como se esse fosse único no mundo - amado. Apelo do rosto do próximo que, em sua urgência ética, adia ou apaga as obrigações que o 'eu interpelado' deve a si próprio e onde a preocupação pela morte de outrem pode, no entanto, ser mais importante para o eu do que a preocupação consigo (LEVINAS, 2005, p. 291)

Rosto aqui não é o conjunto plástico da face humana, olho, nariz e boca. É a vocalização de um sofrimento, tudo que evoca, que demanda uma resposta do Eu e que se sobrepõe às suas próprias necessidades consigo mesmo. Nas palavras do autor, "a relação com o rosto pode, sem dúvida, ser dominada pela percepção, mas o que é especificamente rosto é o que não se reduz a ele” (LEVINAS, 1982, p. 
77). Segundo Levinas (1982), a melhor forma de constituir uma relação social com outrem é sequer se atentar à cor dos olhos, uma vez que, ao enxergarmos apenas as características físicas do rosto, o Outro se torna um objeto. Assim, se a percepção ainda é parte importante da interação com o Outro, esta não deve limitar-se a ela, de modo que o rosto é, portanto, o grito que está além, ele é a própria expressão. "O rosto fala. A manifestação do rosto é já discurso" (2008, p. 54).

Judith Butler (2011) considera que o rosto impõe uma questão ética. Ainda que não possa ser lido em busca de um significado secreto e que seu chamado não possa ser traduzido linguisticamente de modo que entendamos claramente o que devemos fazer, o rosto significa. $O$ rosto não fala no mesmo sentido que a boca, seu chamado não é uma sentença verbal, sua voz é a vocalização de uma agonia. Assim, "expor a mim mesmo à vulnerabilidade do rosto é colocar meu direito ontológico de existir em questão" (BUTLER, 2011, p. 17), visto que, na perspectiva ética, o direito de existir do Outro tem primazia sobre o meu próprio. $\mathrm{O}$ conceito de rosto torna claro, portanto, a centralidade do Outro nas reflexões sobre alteridade de Levinas, "uma primazia condensada no decreto ético: Não matarás, não colocarás em risco a vida do outro." (BUTLER, 2011, p. 17).

Ao compreendermos, a partir de Butler (2011), que o sentido que emerge do rosto não é apreendido pela palavra, mas compele-nos a responder a uma alteridade exigente, podemos perceber que o rosto se constitui em deslocamentos (BUTLER, 2011), o seu sentido escapa, habita o entre. Nessa via, a autora nos revela um paradoxo que se coloca a partir do rosto em Levinas: o rosto não é exclusivamente o rosto humano, mas, ainda assim, ele é a condição para a humanização.

A partir dessa inquietação, a discussão de Butler (2011) aponta para a questão da representação e dá-nos pistas sobre a atuação da mídia tanto em representações que humanizam, como naquelas que desumanizam. Para Levinas (1982), o humano não é representado pelo rosto, pelo contrário, o humano afirma-se na impossibilidade da representação, já que representar é uma forma de reduzir a uma ideia, de tornar objeto, de emoldurar. Estritamente falando, portanto, o rosto não representa nada, no sentido de que falha na captura e entrega daquilo a que ele se refere (BUTLER, 2011). Esse rosto, que não é literalmente um rosto, que é a condição de uma humanização, mas que, no entanto, é uma tentativa de representá-lo, culmina em desumanização, escapa-nos; é o grito que nos escapa, que não conseguimos decodificar, mas ao qual devemos responder. O rosto significa sem representar.

Assim, se a representação desumaniza, as narrativas falham na captura do referente, do grito sôfrego do rosto do Outro; é ao admitir essa falha que é possível se aproximar de uma humanização. O rosto é constituído nessa falha. "Para a representação exprimir o humano, portanto, ela deve não apenas falhar, mas deve mostrar sua falha. Há algo de irrepresentável que nós, não obstante, perseguimos representar e esse paradoxo deve ser absorvido nas representações que realizamos." (BUTLER, 2011, p. 27). Se falhamos na humanização, é, em certa medida, porque insistimos na ideia de que é possível representar a dor do Outro, capturá-la, e insistimos em delinear formas de alcançar o que está além, em sistematizar modelos para encontrar o consenso no heterogêneo, quando a simples admissão da incapacidade nos aproximaria dessa humanização. Afastamo-nos exatamente ao tentar persegui-la, formatá-la.

Ainda que a autora percorra essas pistas em uma reflexão sobre as imagens, é possível estender essa discussão para o nosso interesse aqui: a narrativa jornalística. Podemos, então, pensar a humanização que ocorre para além de uma tentativa de representar o Outro na narrativa jornalística? Os relatos acerca do processo de produção, dos impasses durante a relação com o Outro, das falhas, podem ser compreendidos como formas de humanização? Segundo Butler (2011, p. 31), "a despeito de sua efetividade gráfica, as imagens apontavam para outro lugar, para além delas mesmas, para uma vida e uma precariedade que elas não conseguiam mostrar". Dessa 
maneira, os sentidos que o texto não alcança nos atingem a partir da negativa a uma pretensão de emoldurá-los, quando a impossibilidade de domesticá-los pela escrita está posta, quando nos é estimulado buscar esse grito que está além da materialidade textual. Assim, mostra-se emergencial percorrer rastros que nos auxiliem a estabelecer modos de ver e de que possam responder ao clamor humano à responsabilidade.

\section{Considerações finais}

Se narrar é construir vínculos (MARTINO, 2016), então estudar as narrativas do jornalismo é um modo de resgatar o princípio do compartilhamento, da partilha de sentidos, próprio da comunicação. Em contrapartida, pensar esse narrar como ação do sujeito nos permitiu refletir sobre as relações das quais ele faz parte e as que ele ajuda a constituir, além de nos ajudar a entender como a construção de narrativas nos auxiliam no modo como organizamos a nossa própria experiência de mundo. Nesse sentido, a discussão de Paul Ricoeur (1994) sobre a tríplice mimese é fulcral, uma vez que ela assinala uma concepção de narrativa como ação do sujeito, tendo um mundo prefigurado que lhe serve de base e um retorno ao mundo da experiência pela significação do leitor como direção. Uma concepção de caráter múltiplo assim como a nossa visada da narrativa jornalística.

O Outro que apresentamos aqui é complexo, não permitindo, portanto, uma apropriação total por nenhuma forma de linguagem. Este Outro também não existe a priori, ele só se estabelece a partir da relação, do diálogo com o Si. Tensionamos a relação de alteridade a partir do lugar que o Outro ocupa nas narrativas, um Outro que permanece sempre Outro, mas na direção do qual o jornalista se lança, em busca de um encontro que pode ser transformador para os sujeitos envolvidos no processo que origina a narrativa e que, portanto, integra a lógica mimética de configuração narrativa apontada por Ricoeur (1994).

No entanto, a linguagem possui limitações no que se refere à representação do humano, uma impotência, o que nos apresenta um dilema no âmbito desse estudo, uma vez que por mais que se deseje narrar o Outro, sua complexidade, é impossível alcançá-lo completamente. De forma a fugir desse impasse, seguindo a pista de Butler (2011), sugerimos que a humanização da narrativa jornalística, no que tange as produções que buscam contemplar o Outro, ocorre pela admissão dessa incapacidade de capturar o outro pela linguagem, de representá-lo. Tal movimento ocorre pela abertura dos sentidos, por meio de uma narrativa que não tenta fechar em si os significados, que deixa a cargo do leitor a interpretação e a compreensão dos sujeitos ali presentes.

É também necessário, portanto, um engajamento ético nas nossas pesquisas sobre o jornalismo e a mídia. Ao pesquisarmos os processos de constituição do Outro, por meio da narrativa jornalística, evidencia-se a importância de rastrearmos as marcas desses sujeitos, a fim de compreender o papel exercido pelos indivíduos envolvidos - narrador, personagens e fontes, leitor - no âmbito do processo comunicativo e na construção de sentidos pela narrativa jornalística. Por fim, nos parece pertinente apontar que tal movimento torna possível problematizar a missão do jornalismo no rompimento com lógicas excludentes por intermédio do encontro com o Outro.

\section{Referências}

BUTLER, Judith. Vida precária. Contemporânea - Revista de Sociologia da UFSCar, São Carlos, 1(1), p. 13-33, 2011.

LEAL, Bruno Souza. O jornalismo à luz das narrativas: deslocamentos. In: CARVALHO, Carlos Alberto; LEAL, Bruno. Narrativas e poéticas midiáticas: estudos e perspectivas. São Paulo: Intermeios, 2013, p. 25-47. 
LEAL, Bruno Souza. Saber das narrativas: narrar. In: GUIMARÃES. César; FRANÇA, Vera (Orgs.). Na mídia na rua: narrativas do cotidiano. Belo Horizonte: Autêntica, 2006, p. 19-27.

LEVINAS, Emmanuel. Entre nós: ensaios sobre a alteridade. Petrópolis: Vozes, 2005.

LEVINAS, Emmanuel. Ética e infinito: diálogos com Philippe Nemo. Tradução de João Gama. Lisboa: Ed. 70, 1982.

LEVINAS, Emmanuel. Totalidade e infinito. Tradução de José Pinto Ribeiro. Lisboa: Edições 70, 2008.

MARTINO, Luís Mauro Sá. De um eu ao outro: narrativa, identidade e comunicação com a alteridade. Parágrafo, v. 4, n. 1, p. 40-49. jan/jul 2016.

RESENDE, Fernando. Às desordens e aos sentidos: a narrativa como problema de pesquisa. In: SILVA, Gislene; KÜNSCH, Dimas; BERGER, Christa; ALBUQUERQUE, Afonso. (Org.). Jornalismo Contemporâneo: figurações, impasses e perspectivas. 1.ed. Salvador: Edufba, v. p. 119-138, 2011.

RESENDE, Fernando. O Jornalismo e suas Narrativas: as Brechas do Discurso e as Possibilidades de Encontro. Revista Galáxia, São Paulo, n.18, p. 31-43, 2009.

RESENDE, Fernando. Representação das diferenças no discurso jornalístico. Brazilian Journalism Research, v. II, n. 2, p. 206-223, 2014.

RICOEUR, Paul. O si-mesmo como um outro. Trad. Luci Moreira Cesar. Campinas: Papirus, 1991.

RICOEUR, Paul. Tempo e Narrativa I. A tríplice Mimese, São Paulo, Papirus, 1994.

SCHWAAB, Reges. Jornalismo, interrupção: sondar, narrar, reconhecer. In: PICCININ, Fabiana; SOSTER, Demétrio Azeredo (Orgs). Narrativas comunicacionais complexificadas 2: a forma. Santa Cruz do Sul: EDUNISC, 2014, p. 32-53.

TODOROV, Tzvetan. A conquista da América: a questão do outro. São Paulo: Martins Fontes, 1983. 